\title{
Correlation between plasma homocysteine and first myocardial infarction in young patients: Case-control study in Constanta County, Romania
}

\author{
CRISTINA NEDELCU ${ }^{1}$, MIHAELA IONESCU ${ }^{2}$, ANCA PANTEA-STOIAN $^{3}$, DANIEL NIŢÄ ${ }^{4 *}$, LUCIAN PETCU $^{5}$, \\ LAURA MAZILU $^{2 *}$, ANDRA-IULIA SUCEVEANU ${ }^{2}$, LILIANA-ANA TUŢA ${ }^{2 *}$ and IRINEL-RALUCA PAREPA ${ }^{2}$ \\ ${ }^{1}$ Cardiology Department, Constanta County Army Hospital; ${ }^{2}$ Department of Clinical Medical Sciences, \\ Faculty of General Medicine, 'Ovidius’ University of Constanţa, 900527 Constanţa; \\ ${ }^{3}$ Department of Metabolic Diseases of The Clinical Emergency Hospital, 'Carol Davila' University \\ of Medicine and Pharmacy Bucharest, 050474 Bucharest; ${ }^{4}$ Department of Interventional Cardiology, \\ Army's Center for Cardiovascular Diseases, 010825 Bucharest; ${ }^{5}$ Department of Biophysics, \\ Faculty of General Medicine, 'Ovidius’ University of Constanţa, 900527 Constanţa, Romania
}

Received September 30, 2020; Accepted October 30, 2020

DOI: $10.3892 /$ etm.2020.9533

\begin{abstract}
An elevated level of total plasma homocysteine has been associated with a higher risk of atherosclerosis and coronary heart disease. The aim of our research was to study the relation between homocysteine and myocardial infarction (MI) in young patients. We conducted a case-control study in Constanţa County, Romania including 61 patients, divided in two groups. The first group, the MI group, consisted of 28 patients, male $(67.9 \%)$ and female $(32.1 \%)$ aged less than 45 years who were consecutively admitted to the Intensive Coronary Care Unit of the Emergency County Hospital of Constanţa from September 1, 2017 to August 31, 2018 (12 months), with an established diagnosis of first acute MI. The second group, the control group, included 33 patients, male (75.8\%) and female $(24.2 \%)$ aged less than 45 years, with cardiovascular risk factors and/or stable angina pectoris that were consecutively addressed for ambulatory cardiac evaluation at the Outpatient Clinic of Emergency County Hospital of Constanţa during the same period. Fasting plasma homocysteine was determined in both groups, within $24 \mathrm{~h}$ after MI onset, respectively after first cardiac exam in the controls. High homocysteine was statistically confirmed to be a risk factor in the study group, especially
\end{abstract}

Correspondence to: Professor Irinel-Raluca Parepa or Dr Mihaela Ionescu, Department of Clinical Medical Sciences, Faculty of General Medicine, 'Ovidius' University of Constanţa, 124 Bd. Mamaia, 900527 Constanţa, Romania

E-mail: irinel_parepa@yahoo.com

E-mail: ciucea_mihaela@yahoo.com

*Contributed equally

Key words: homocysteine, atherosclerosis, arteriosclerosis, myocardial infarction, patients less than 45 years in association with smoking, chronic kidney disease (CKD), and to a lesser extent with diabetes mellitus (DM) and hypertension. Data analysis was performed using IBM SPSS Statistics 23. The procedures used included descriptive statistics, parametric statistical tests (Independent sample t-test), non-parametric statistical tests [Chi-square test of the association, with the evaluation of odds ratio (OR)]; the significance level used in the analysis (P-value) was 0.05. After adjusting for variables, our study results pointed out a strong association between plasma homocysteine and first acute MI among young patients, emphasising plasma homocysteine as a possible risk factor for myocardial infarction.

\section{Introduction}

An elevated level of total homocysteine is known to be associated with a higher risk for cardiovascular disease (1). McCully was the first one to report an association between elevated levels of homocysteine and arterial damages (2). He reported two cases of premature atherosclerosis and arterial thrombosis in children with elevated levels of homocysteinemia and homocysteinuria. He concluded that increased concentrations of homocysteine could be responsible for premature atherosclerotic vascular disease. These children were found to have an inborn error in homocysteine metabolism and had extremely high levels of plasma homocysteine. In other studies, the methylene tetrahydrofolate reductase (MTHFR) 677T polymorphism was demonstrated to cause the strongest modulation of total homocysteinemia of all genes associated with homocysteine and folate metabolism (3-5). The aim of the present study was to investigate whether the risk for myocardial infarction (MI) is increased by elevated levels of plasma homocysteine in patients aged less than 45 years.

\section{Patients and methods}

Our study included 28 patients $\leq 45$ years of age who suffered a first MI (MI group) and 33 patients matched in regards to 
age, sex, and risk factors (control group). All subjects were Romanians. Exposure items were assessed, including lifestyle [smoking status, obesity (calculation of body mass index (BMI) and physical activity (MET levels), medical history [diabetes mellitus (DM), hypertension, previous cardiovascular disease (CV) and chronic kidney disease (CKD)] and laboratory tests (serum LDL-cholesterol). We determined the plasma levels of homocysteine by enzymatic method, within $24 \mathrm{~h}$ after MI onset, respectively within $24 \mathrm{~h}$ after first cardiac exam in the controls (cut-off value $15 \mu \mathrm{mol} / \mathrm{l}$ ).

Statistical analysis. Data analysis was performed using IBM SPSS Statistics version 23 (IBM Corp.). The procedures used included descriptive statistics, parametric statistical tests (independent sample t-test), non-parametric statistical tests [Chi-square test of the association, with the evaluation of odds ratio (OR)], adjustments for accounted variables. The significance level used in the analysis (P-value) was 0.05 .

\section{Results}

Patient frequency is depicted in Table I. Both study groups were statistically balanced $[\mathrm{P}=0.522>\alpha=0.05$ (one sample Chi-square test)].

Ages (mean, minimum and maximum) across the study groups are documented in Table II. There were no mean age differences between the two studied groups $[\mathrm{P}=0.699>\alpha=0.05$ (one sample Chi-square test)].

There was no significant statistical difference between sex distributions between the study groups $[\mathrm{P}=0.625>\alpha=0.05$ (one sample Chi-square test)] (Table III).

We found a higher prevalence of smoking status in the MI group [OR, 4.4; 95\% confidence interval $(\mathrm{CI})=1.417-13.666$; $\left.\chi^{2}=6.961, \mathrm{P}=0.008\right)$ as shown in Table IV. Hypertensive subjects were $64.3 \%$ in the MI group vs. $36.4 \%$ in the control group (Table IV), being slight significantly more numerous $\left(\chi^{2}=4.725\right.$, $\mathrm{P}=0.030)$ in the $\mathrm{MI}$ group (OR, 3.15; 95\% CI=1.103-8.993).

Obesity had a similar frequency $\left(\chi^{2}=0.286, \mathrm{P}=0.593\right)$ in both study lots (OR, 0.754; 95\% CI=0.267-2.125). In addition, we found no significant differences for LDL-cholesterol serum levels $\left(\chi^{2}=2.382, \mathrm{P}=0.123\right)(\mathrm{OR}, 0.427 ; 95 \% \mathrm{CI}=0.143-1.272)$. Physical activity level was sensitively equal $\left(\chi^{2}=1.125\right.$, $\mathrm{P}=0.289)$ across both groups $(\mathrm{OR}, 1.759 ; 95 \% \mathrm{CI}=0.617-5.018)$ (Table V).

We also studied the prevalence of high cardiovascular risk conditions such as DM, CKD and pre-existent $\mathrm{CV}$ disease in both groups. There was a significantly higher prevalence of pre-existent cardiovascular $(\mathrm{CV})$ disease in the control group vs. the MI group (33.3 vs. 10.7\%) showing a negative correlation with the index event in the MI group (Table VI). DM $\left(\chi^{2}=4.560, \mathrm{P}=0.033\right.$, OR, 3.624; 95\% $\left.\mathrm{CI}=1.073-12.235\right)$ and CKD $\left(\chi^{2}=6.879, \mathrm{P}=0.009, \mathrm{OR}, 4.286\right.$; 95\% CI=1.402-13.098) were more prevalent among subjects from the MI group (Table VI).

Finally, we found a significantly higher prevalence for increased homocysteinemia (cut-off value $15 \mu \mathrm{mol} / \mathrm{l}$ ) among patients from the MI group $\left(\chi^{2}=17.632, \mathrm{P}<0.001\right)$, showing a strong correlation between hyperhomocysteinemia and index event in the MI group (OR, 11.822; 95\% CI=3.425-40.802) (Table VII).
Table I. Frequencies in the study groups.

\begin{tabular}{lccc}
\hline Study group & Frequency & Percent & Valid percent \\
\hline MI group & 28 & 45.9 & 45.9 \\
Controls & 33 & 54.1 & 54.1 \\
\hline
\end{tabular}

MI, myocardial infarction.

Table II. Mean, maximum and minimum age (years) across the study groups.

\begin{tabular}{lcccc}
\hline & \multicolumn{4}{c}{ Age (years) } \\
\cline { 2 - 5 } Study group & Minimum & Maximum & Mean & SD \\
\hline MI group & 29.00 & 45.00 & 40.0714 & 5.08395 \\
Controls & 31.00 & 45.00 & 40.5152 & 3.54543 \\
\hline
\end{tabular}

MI, myocardial infarction; SD, standard deviation.

Table III. Sex distribution of the two studied groups.

\begin{tabular}{llc}
\hline & \multicolumn{2}{c}{ Sex } \\
\cline { 2 - 3 } Study group & Male & Female \\
\hline MI group & & \\
Count & 19 & 9 \\
$\%$ within lot & $67.9 \%$ & $32.1 \%$ \\
$\%$ of total & $31.1 \%$ & $14.8 \%$ \\
Controls & & 8 \\
Count & 25 & $24.2 \%$ \\
$\%$ within lot & $75.8 \%$ & $13.1 \%$ \\
\hline of total & $41.0 \%$ & \\
\hline
\end{tabular}

MI, myocardial infarction.

\section{Discussion}

In young patients with myocardial infarction (MI), the evidence of atherosclerotic coronary disease is not always discernible, which highlights a potential importance of prothrombotic risk factors $(6,7)$. World-wide research regarding the role of homocysteine in favoring ischemic heart disease (IHD) has provided controversial results. Some studies have suggested that hyperhomocysteinemia is an independent risk factor for IHD, especially acute ST elevation MI (8-12), while others revealed no association between hyperhomocysteinemia and acute MI (13-15).

In our case-control study, we evaluated the association between an increased level of homocysteinemia and first MI in patients aged less than 45 years. Our results showed a significant $(\mathrm{P}<0.001)$ risk for $\mathrm{MI}$ in patients with a high fasting plasma homocysteine levels (OR, 11.822; 95\% CI=3.425-40.802). It was 
Table IV. Smoking and hypertension status across the study groups.

\begin{tabular}{|c|c|c|c|c|c|}
\hline \multirow[b]{2}{*}{ Study group } & \multicolumn{2}{|c|}{ Smoking } & \multicolumn{2}{|c|}{ Hypertension } & \multirow[b]{2}{*}{ Total } \\
\hline & Yes & No & Yes & No & \\
\hline \multicolumn{6}{|l|}{ MI group } \\
\hline Count & 22 & 6 & 18 & 10 & 28 \\
\hline$\%$ within lot & $78.6 \%$ & $21.4 \%$ & $64.3 \%$ & $35.7 \%$ & $100.0 \%$ \\
\hline$\%$ of total & $36.1 \%$ & $9.8 \%$ & $29.5 \%$ & $16.4 \%$ & $45.9 \%$ \\
\hline \multicolumn{6}{|l|}{ Controls } \\
\hline Count & 15 & 18 & 12 & 21 & 33 \\
\hline$\%$ within lot & $45.5 \%$ & $54.5 \%$ & $36.4 \%$ & $63.6 \%$ & $100.0 \%$ \\
\hline$\%$ of total & $24.6 \%$ & $29.5 \%$ & $19.7 \%$ & $34.4 \%$ & $54.1 \%$ \\
\hline
\end{tabular}

MI, myocardial infarction.

Table V. Obesity, serum LDL-cholesterol levels (cut-off value $100 \mathrm{mg} / \mathrm{dl}$ ) and physical activity across study groups.

\begin{tabular}{|c|c|c|c|c|c|c|c|}
\hline \multirow[b]{2}{*}{ Study group } & \multicolumn{2}{|c|}{ Obesity } & \multicolumn{2}{|c|}{ LDL-cholesterol } & \multicolumn{2}{|c|}{ Physical activity } & \multirow[b]{2}{*}{ Total } \\
\hline & Yes & No & Yes & No & Yes & No & \\
\hline \multicolumn{8}{|l|}{ MI group } \\
\hline Count & 10 & 18 & 16 & 12 & 19 & 9 & 28 \\
\hline$\%$ within lot & $35.7 \%$ & $64.3 \%$ & $57.1 \%$ & $42.9 \%$ & $67.9 \%$ & $32.1 \%$ & $100.0 \%$ \\
\hline$\%$ of total & $16.4 \%$ & $29.5 \%$ & $26.2 \%$ & $19.7 \%$ & $31.1 \%$ & $14.8 \%$ & $45.9 \%$ \\
\hline \multicolumn{8}{|l|}{ Control group } \\
\hline Count & 14 & 19 & 25 & 8 & 18 & 15 & 33 \\
\hline$\%$ within lot & $42.4 \%$ & $57.6 \%$ & $75.8 \%$ & $24.2 \%$ & $54.5 \%$ & $45.5 \%$ & $100.0 \%$ \\
\hline$\%$ of total & $23.0 \%$ & $31.1 \%$ & $41.0 \%$ & $13.1 \%$ & $29.5 \%$ & $24.6 \%$ & $54.1 \%$ \\
\hline
\end{tabular}

MI, myocardial infarction.

Table VI. Pre-existent CV disease, DM and CKD across the study groups.

\begin{tabular}{|c|c|c|c|c|c|c|c|}
\hline \multirow[b]{2}{*}{ Study group } & \multicolumn{2}{|c|}{ Pre-existent $\mathrm{CV}$ disease } & \multicolumn{2}{|c|}{$\mathrm{DM}$} & \multicolumn{2}{|c|}{ CKD } & \multirow[b]{2}{*}{ Total } \\
\hline & Yes & No & Yes & No & Yes & No & \\
\hline \multicolumn{8}{|l|}{ MI group } \\
\hline Count & 3 & 25 & 11 & 17 & 15 & 13 & 28 \\
\hline$\%$ within lot & $10.7 \%$ & $89.3 \%$ & $39.3 \%$ & $60.7 \%$ & $53.6 \%$ & $46.4 \%$ & $100.0 \%$ \\
\hline$\%$ of total & $4.9 \%$ & $41.0 \%$ & $18.0 \%$ & $27.9 \%$ & $24.6 \%$ & $21.3 \%$ & $45.9 \%$ \\
\hline \multicolumn{8}{|l|}{ Control group } \\
\hline Count & 11 & 22 & 5 & 28 & 7 & 26 & 33 \\
\hline$\%$ within lot & $33.3 \%$ & $66.7 \%$ & $15.2 \%$ & $84.8 \%$ & $21.2 \%$ & $78.8 \%$ & $100.0 \%$ \\
\hline$\%$ of total & $18.0 \%$ & $36.1 \%$ & $8.2 \%$ & $45.9 \%$ & $11.5 \%$ & $42.6 \%$ & $54.1 \%$ \\
\hline
\end{tabular}

MI, myocardial infarction; CV, previous cardiovascular disease; CKD, chronic kidney disease; DM, diabetes mellitus.

the strongest risk factor in our MI case study group, followed by smoking (OR, 4.4; 95\% CI=1.417-13.666), chronic kidney disease (CKD) (OR, 4.286; 95\% CI=1.402-13.098), diabetes mellitus (DM) (OR, 3.624; 95\% CI=1.073-12.235) and hypertension (OR, 3.15; 95\% CI=1.103-8.993). Other traditional cardiovascular risk factors (obesity, high LDL-cholesterol 
Table VII. Homocysteine cut-off distribution across the studied groups.

\begin{tabular}{llcc}
\hline & \multicolumn{2}{c}{ Homocysteine } & \\
\cline { 2 - 3 } Study group & Yes & No & Total \\
\hline MI group & & & \\
Count & 19 & 9 & 28 \\
$\%$ within lot & $67.9 \%$ & $32.1 \%$ & $100.0 \%$ \\
$\%$ of total & $31.1 \%$ & $14.8 \%$ & $45.9 \%$ \\
Control group & & & \\
Count & 5 & 28 & 33 \\
$\%$ within lot & $15.2 \%$ & $84.8 \%$ & $100.0 \%$ \\
$\%$ of total & $8.2 \%$ & $45.9 \%$ & $54.1 \%$ \\
\hline
\end{tabular}

MI, myocardial infarction.

levels and sedentary lifestyle) were equal across the MI and control groups.

Pathophysiological background of these findings is supported by the 'arteriosclerosis' theory, previously expressed by McCully (2). Significant stiffness and damage but without lipid storages, atherosclerotic plaque and fibrosis (similar to common atherosclerosis in older adulthood) were the modifications in the arterial walls observed in children with homocystinuria (16). Thus, elevated total plasma homocysteine may lead to vascular occlusion, either by thromboembolic events, or by arterial damage due to endothelial dysfunction (17).

High homocysteine plasma concentration is particularly associated with renal function impairment $(18,19)$, and this rationally explains the association between these two risk factors that we found in our study. Another factor for hyperhomocysteinemia is a common polymorphism (C677T) in methylenetetrahydrofolate reductase (MTHFR), which induces high thermolability of the enzyme and high susceptibility to insufficient folate levels; $\sim 12 \%$ of the white population is homozygous (TT genotype) (15), and this status may be associated with hyperhomocysteinemia especially when combined with poor folate (and vitamin B12) intake $(15,20)$. Yet, reports concerning either homozygous or heterozygous subjects did not show any association of high homocysteine plasma levels and IHD (15,21-23).

It was demonstrated that homocysteine enhances oxidative stress (24), and consecutively promotes endothelial dysfunction, with altered NO-dependent vasodilatation $(25,26)$. These findings may explain the association between hyperhomocysteinemia and hypertension as risk factors in our MI case group. Regarding coronary flow, an inverse relationship has also been demonstrated between homocysteinemia and endothelium-dependent blood flow, especially in young patients (27), results that corroborate our findings and may rationally explain it. On the other hand, the relationship between mild hyperhomocysteinemia and IHD may be inverse as atherosclerosis (especially in the setting of hypertension and DM) accelerates the fall in renal function, thus increasing plasma levels of homocysteine (28). Even if reducing very high plasma homocysteine concentrations in patients decreases cardiovascular risk (29), this may be due to folate replacement, and not to the correction of hyperhomocysteinemia itself $(30,31)$.

In conclusion, our findings support a strong association between elevated homocysteine plasma levels and first MI in young patients, mainly with no previously diagnosed cardiovascular disease, but with other significantly prevalent cardiovascular risk factors such as smoking, CKD, hypertension, and DM.

\section{Acknowledgements}

Not applicable.

\section{Funding}

No funding was received for this research.

\section{Availability of data and materials}

Data used in the current original study were obtained from patient archive files, Constanţa County Emergency Hospital, Romania. Any further information regarding the present study is available from the corresponding author upon reasonable request.

\section{Authors' contributions}

$\mathrm{CN}$, AIS and LM designed the study and collected data from recruited cases. DN performed the arteriographies and angioplasties. LP, APS and LAT analyzed data and performed the statistics. MI and IRP analysed and wrote the Results and Discussion section including the literature review, prepared the manuscript, translated it and managed all the correspondence for publishing. All authors read and approved the final manuscript.

\section{Ethics approval and consent to participate}

This non-interventional study was approved by the local Ethics Commission of Constanța County Emergency Hospital, Romania (no. 29/24.08.2017).

\section{Patient consent for publication}

Not applicable.

\section{Competing interests}

There are no competing interests regarding the authors of this research.

\section{References}

1. Clarke R, Daly L, Robinson K, Naughten E, Cahalane S, Fowler B and Graham I: Hyperhomocysteinemia: An independent risk factor for vascular disease. N Engl J Med 324: 1149-1155, 1991.

2. McCully KS: Vascular pathology of homocysteinemia: Implications for the pathogenesis of arteriosclerosis. Am J Pathol 56: 111-128, 1969. 
3. Frosst P, Blom HJ, Milos R, Goyette P, Sheppard CA, Matthews RG, Boers GJ, Den Heijer M, Kluijtmans LA, Van den Heuvel LP, et al: A candidate genetic risk factor for vascular disease: A common mutation in methylenetetrahydrofolate reductase. Nature Genet 10: 111-113, 1995.

4. Sharma P, Senthilkumar RD, Brahmachari V, Sundaramoorthy E, Mahajan A, Sharma A and Sengupta S: Mining literature for a comprehensive pathway analysis: A case study for retrieval of homocysteine related genes for genetic and epigenetic studies. Lipids Health Dis 5: 1, 2006.

5. Rudreshkumar KJ, Majumdar V, Nagaraja D and Christopher R: Relevance of plasma levels of free homocysteine and methionine as risk predictors for ischemic stroke in the young. Clin Nutr 37: 1715-1721, 2018

6. Chan MY, Andreotti F and Becker RC: Hypercoagulable states in cardiovascular disease. Circulation 118: 2286-2297, 2008.

7. Rossini R, Capodanno D, Lettieri C, Musumeci G, Limbruno U, Molfese M, Spatari V, Calabria P, Romano M, Tarantini G, et al: Long-term outcomes of patients with acute coronary syndrome and nonobstructive coronary artery disease. Am J Cardiol 112: 150-155, 2013

8. Akyürek Ö, Akbal E and Güneş F: Increase in the risk of ST elevation myocardial infarction is associated with homocysteine level. Arch Med Res 45: 501-506, 2014

9. Ma Y, Peng D, Liu C, Huang C and Luo J: Serum high concentrations of homocysteine and low levels of folic acid and vitamin $B_{12}$ are significantly correlated with the categories of coronary artery diseases. BMC Cardiovasc Disord 17: 37, 2017.

10. Anand SS, Yusuf S, Vuksan V, Devanesen S, Teo KK Montague PA, Kelemen L, Yi C, Lonn E, Gerstein H, et al: Differences in risk factors, atherosclerosis, and cardiovascular disease between ethnic groups in Canada: The study of health assessment and risk in ethnic groups (SHARE). Lancet 356 : 279-284, 2000

11. Ramesh N and Ganesan K: A study on serum homocysteine as an independent risk factor for coronary artery disease. IAIM 6 : 75-80, 2019.

12. Bautista LE, Arenas IA, Penuela A and Martinez LX: Total plasma homocysteine level and risk of cardiovascular disease: A meta-analysis of prospective cohort studies. J Clin Epidemiol 55 882-887, 2002

13. Chen CY, Yang TC, Chang C, Lu SC and Chang PY: Homocysteine is a bystander for ST-segment elevation myocardial infarction: A case-control study. BMC Cardiovasc Disord 18: 33, 2018.

14. Deepa R, Velmurugan K, Saravanan G, Karkuzhali K, Dwarakanath V and Mohan V: Absence of association between serum homocysteine levels and coronary artery disease in South Indian males. Indian Heart J 53: 44-47, 2001.

15. Brattström L, Wilcken DE, Ohrvik J and Brudin L: Common methylenetetrahydrofolate reductase gene mutation leads to hyperhomocysteinemia but not to vascular disease: The result of a meta-analysis. Circulation 98: 2520-2526, 1998.

16. Bergheanu SC, Bodde MC and Jukema JW: Pathophysiology and treatment of atherosclerosis: Current view and future perspective on lipoprotein modification treatment. Neth Heart J 25: 231-242, 2017.

17. Brattström L and Wilcken DE: Homocysteine and cardiovascular disease: Cause or effect? Am J Clin Nutr 72: 315-323, 2000.

18. Arnadottir M, Hultberg B, Nilsson-Ehle P and Thysell H: The effect of reduced glomerular filtration rate on plasma total homocysteine concentration. Scand J Clin Lab Invest 56: 41-46, 1996.
19. Guttormsen AB, Ueland PM, Svarstad E and Refsum H: Kinetic basis of hyperhomocysteinemia in patients with chronic renal failure. Kidney Int 52: 495-502, 1997.

20. Stabler SP, Marcell PD, Podell ER, Allen RH, Savage DG and Lindenbaum J: Elevation of total homocysteine in the serum of patients with cobalamin or folate deficiency detected by capillary gas chromatography-mass spectrometry. J Clin Invest 81: 466-474, 1988.

21. Verhoef P, Rimm EB, Hunter DJ, Chen J, Willett WC, Kelsey K and Stampfer MJ: A common mutation in the methylenetetrahydrofolate reductase gene and risk of coronary heart disease: Results among U.S. men. J Am Coll Cardiol 32: 353-359, 1998.

22. Tsai MY, Welge BG, Hanson NQ, Bignell MK, Vessey J, Schwichtenberg K, Yang F, Bullemer FE, Rasmussen R and Graham KJ: Genetic causes of mild hyperhomocysteinemia in patients with premature occlusive coronary artery diseases. Atherosclerosis 143: 163-170, 1999.

23. Folsom AR, Nieto FJ, McGovern PG, Tsai MY, Malinow MR, Eckfeldt JH, Hess DL and Davis CE: Prospective study of coronary heart disease incidence in relation to fasting total homocysteine, related genetic polymorphisms, and B vitamins: The atherosclerosis risk in communities (ARIC) study. Circulation 98: 204-210, 1998.

24. Kanani PM, Sinkey CA, Browning RL, Allaman M, Knapp HR and Haynes WG: Role of oxidant stress in endothelial dysfunction produced by experimental hyperhomocyst(e)inemia in humans. Circulation 100: 1161-1168, 1999.

25. Celermajer DS, Sorensen K, Ryalls M, Robinson J, Thomas O, Leonard JV and Deanfield JE: Impaired endothelial function occurs in the systemic arteries of children with homozygous homocystinuria but not in their heterozygous parents. J Am Coll Cardiol 22: 854-858, 1993.

26. Bellamy MF, McDowell IF, Ramsey MW, Brownlee M, Newcombe RG and Lewis MJ: Oral folate enhances endothelial function in hyperhomocysteinaemic subjects. Eur J Clin Invest 29: 659-662, 1999.

27. Schächinger V, Britten MB, Elsner M, Walter DH, Scharrer I and Zeiher AM: A positive family history of premature coronary artery disease is associated with impaired endothelium-dependent coronary blood flow regulation. Circulation 100: 1502-1508, 1999.

28. Potter K, Hankey GJ, Green DJ, Eikelboom JW and Arnolda LF: Homocysteine or renal impairment: Which is the real cardiovascular risk factor? Arterioscler Thromb Vasc Biol 28: 1158-1164, 2008.

29. Wilcken DE and Wilcken B: The natural history of vascular disease in homocystinuria and the effects of treatment. J Inherit Metab Dis 20: 295-300, 1997.

30. Durga J, Bots ML, Schouten EG, Kok FJ and Verhoef P: Low concentrations of folate, not hyperhomocysteinemia, are associated with carotid intima-media thickness. Atherosclerosis 179: 285-292, 2005

31. Brown KS, Huang Y, Lu ZY, Jian W, Blair IA and Whitehead AS: Mild folate deficiency induces a proatherosclerotic phenotype in endothelial cells. Atherosclerosis 189: 133-141, 2006. 